\title{
Ultrastructural analysis of cardiomyocytes shows that loss of left ventricular desmosomes leads to shortening of ST segment time in patients with arrhythmogenic cardiomyopathy
}

\section{Yuan Chang \\ Wuhan Union Hospital}

Xiumeng Hua

Chinese Academy of Medical Sciences \& Peking Union Medical College Fuwai Hospital

\section{Yiqing $\mathrm{Hu}$}

Chinese Academy of Medical Sciences \& Peking Union Medical College Fuwai Hospital

\section{Wendao Liu}

Chinese Academy of Medical Sciences \& Peking Union Medical College Fuwai Hospital

\section{Xiao Chen}

Chinese Academy of Medical Sciences \& Peking Union Medical College Fuwai Hospital

\section{Xuexin Fan}

Chinese Academy of Medical Sciences \& Peking Union Medical College Fuwai Hospital

\section{Tao. Menghao}

Chinese Academy of Medical Sciences \& Peking Union Medical College Fuwai Hospital

Shi Chen

Chinese Academy of Medical Sciences \& Peking Union Medical College Fuwai Hospital

Jiangping Song ( $\nabla$ fwsongjiangping@126.com )

Huangzhong University of Science and Technology https://orcid.org/0000-0002-9782-3323

\section{Shengshou Hu}

Chinese Academy of Medical Sciences \& Peking Union Medical College Fuwai Hospital

\section{Research article}

Keywords: Arrhythmogenic cardiomyopathy, Ultrastructural features, Desmosome, Electrocardiogram, Mitochondrion

Posted Date: October 26th, 2020

DOI: https://doi.org/10.21203/rs.3.rs-93392/v1 
License: (c) (i) This work is licensed under a Creative Commons Attribution 4.0 International License. Read Full License 


\section{Abstract}

Background: Arrhythmogenic cardiomyopathy (AC) is an inherited myocardial disease affecting the both ventricles. It shows large heterogeneity on its clinical, genetic, and pathological manifestations. The intercalated disc remodeling has been investigated in right ventricle (RV) of $A C$, however, the ultrastructural features in left ventricle (LV) and among different genotypes remain unknown.

Methods: The ultrastructure characters of both ventricles from 24 AC who fulfilled the international Task Force diagnostic and 10 normal donor hearts were studied by transmission electron microscope. We applied Pearson correlation analysis to identify the relationship between $\mathrm{D}$ structure and electrocardiogram changes.

Results: These 24 patients were divided into two subtypes based on whether they carried desmosome (D) gene mutation. We found that more $D$ structures in LV than that in the right ventricles (RV) in the normal hearts (LV vs. RV, $10.82 \pm 3.12 \%$ vs. $6.75 \pm 1.11 \%, \mathrm{p}=0.001$ ), but the density (AC vs. Control, $3.77 \pm 1.58$ per $10 \mu \mathrm{m}$ vs. $4.21 \pm 1.76$ per $10 \mu \mathrm{m}, \mathrm{p}=0.001$ ) and proportion (AC vs. Control, $6.65 \pm 2.77 \%$ vs. $10.82 \pm$ $3.12 \%, p=0.001$ ) of $D$ was declined in LV of AC compared with that in normal hearts. The width (AC vs. Control, $21.38 \pm 2.31 \mathrm{~nm}$ vs. $18.09 \pm 0.98 \mathrm{~nm}, \mathrm{p}=0.001$ ) and length (AC vs. Control, $0.17 \pm 0.05 \mu \mathrm{m}$ vs. $0.14 \pm 0.01 \mu \mathrm{m}, \mathrm{p}=0.002$ ) of $\mathrm{D}$ was increased in RV of AC compared with that in normal hearts. Destroyed $D$ structures were found in all AC patients, regardless of carrying a D gene mutation or not. The proportion of $D$ in LV are positively correlated with ST segment time in AC patients. The ultrastructure of mitochondria was not different between $\mathrm{AC}$ and normal hearts.

Conclusions: The D remodeling patterns had no correlation with the type of mutation. The D of LV mainly showed a decrease in density and proportion, but the $\mathrm{D}$ of RV were mainly manifested as compensatory widening and lengthening. The D loss in LV may cause ST segment shortening. From the perspective of ultrastructure, we concluded that increased output power of heart may accelerate the desmosome remodeling or disintegration.

\section{Background}

Arrhythmogenic cardiomyopathy (AC) is an inherited myocardial disease characterized by fibrofatty myocardial replacement majorly in right ventricle $(\mathrm{RV})$, which major clinical presentations are malignant ventricular arrhythmia and heart failure ${ }^{1}$. AC is a genetically heterogeneous disorder, and the desmosome (D) genes mutation such as $P K P 2, D S P, D S G 2, D S C 2$ and JUP is the most common cause of AC, which are most inherited in an autosomal dominant pattern ${ }^{2}$. Except the $D$, the area composita is a mixed junctional structure composed of both desmosomal and adherens junctional proteins, therefore, mutations in nondesmosomal gene (CTNNA3, $C D H 2$ ) have been identified in probands without pathogenic desmosomal mutations $^{3-5}$. The genetic causes of $\mathrm{AC}$ are complicated as more non-junctional structure genes mutations leading to AC, such as LMNA, TMEM43, DES, PLN and SCN5A have been reported ${ }^{2}$. Consistently, patients with different genotypes exhibited different phenotype and prognosis ${ }^{6}$. The 
distribution and extent of fibrofatty replacement of the myocardium are heterogeneous between individuals, and vary between right and left ventricle.

The ultrastructure characters of RV from AC have been investigated previously, but the ultrastructure characters in LV of $A C$ and the difference between left and right ventricle remained largely unknown ${ }^{7}$. The relationship between the $D$ structure and the genetic background is also unclear.

In this study, we performed electron microscopy on 24 explanted AC hearts and 10 normal hearts to investigate the ultrastructural features of left and right ventricle in AC. These 24 patients with AC were divided into two groups according to whether they carried $D$ gene mutation or not (D gene mutation positive group (DP group, $n=10$ ) and $D$ gene mutation negative group (DN group, $n=14)$ ). We found the $D$ remodeling patterns had no correlation with the type of mutation. We perform Pearson correlation analysis to reveal the relationship between $D$ remodeling and electrophysiological remodeling. The $D$ loss in LV may cause ST segment shortening. From the perspective of ultrastructure, we concluded that increased output power of heart may accelerate the desmosome remodeling or disintegration.

\section{Methods}

\section{Patients}

A total of 24 heart transplant ( $\mathrm{HTx}$ ) patients diagnosed as AC according to 2010 International Task Force Criteria between 2005 and 2018 were enrolled in this study, and both ventricles of the diagnosed patients were collected. At same time, the basic clinical characteristics and family history were also collected. 10 organ donor patients with normal cardiac function where the heart was not suit for transplantation for non-cardiac factors (mismatched blood types or heart sizes) served as controls. This study complied with the ethical guidelines of the 1975 Declaration of Helsinki. All participants provided written informed consent at the time of enrollment.

\section{Histology}

Right and Left ventricles of explanted hearts were fixated in 10\% formalin and embedded with paraffin. 4 $\mu \mathrm{m}$-thick paraffin-embedded sections were serially cut and stained by hematoxylin-eosin and Masson trichrome.

\section{Genetic analysis}

The gene mutation of each patient was identified through Gene panel or Whole Genome Sequencing (WGS) analysis. All patients were screened through gene panel with known cardiomyopathy-related gene mutations first, if no known gene mutation was identified, then the WGS was conducted to dig gene mutation information deeply.

\section{Electrocardiography}


For the evaluation of electrocardiography (ECG) parameters, we selected the latest ECG recordings prior to transplantation surgery in the HTx cohort. The 12-lead ECGs (filter range 0.05 to $150 \mathrm{~Hz}$; AC filter $50 \mathrm{~Hz}$, $25 \mathrm{~mm} / \mathrm{s}, 10 \mathrm{~mm} / \mathrm{mV}$ ) were evaluated by two independent senior electrophysiology experts from the Cardiac Arrhythmia Center of Fuwai Hospital, who were blinded to the clinical, pathological and genetic information. QT correction in atrial fibrillation was measured as previously reported ${ }^{8}$. Patients with pacemaker implantation were excluded from ECG measurement.

\section{Transmission electron microscopy and measure}

The ultrathin section of transplanted heart tissue was made as described before ${ }^{13}$, the process was described briefly as following: both ventricles of transplanted heart tissue were routinely fixed in $2.5 \%$ glutaraldehyde in $0.1 \mathrm{M} / \mathrm{L}$ phosphate buffer $(\mathrm{pH} 7.3)$ and post-fixed in buffered $1 \%$ osmium tetroxide. The samples were dehydrated in a series of ethanol and embedded in Epon. Semi-thin sections were first evaluated at light microscope before proceeding to ultrathin sections. Thin sections were stained with uranyl acetate and lead citrate, and examined under JEM-1400Flash transmission electron microscope.

As far as intercalated discs are concerned, random fields of many longitudinally sectioned myocytes were analyzed to obtain a total of 10 intercalated discs per patients. Intercalated discs were first photographed at low magnification of X6000 to make the panoramic photography of intercalated discs, then further analysis at a final magnification of $X 30000$. The characters of intercalated discs were measured by the reported methods with the help of Image-J, including contour length, end to end distance, length of $D$, gap of $D$, length of gap junction, and gap of fascia adheres, then convolution index was expressed as the contour length of intercalated disc divided by the end-to-end distance, and $D$ and gap junction percent length of intercalated disc, $D$ and gap junction number per $10 \mu \mathrm{m}$ unit length of intercalated disc were also

calculated ${ }^{2,3}$.At the same time, the light density value, area and quantity of mitochondrial were evaluated as the previous method by three authors, who were blinded to the clinical background of the individuals ${ }^{9}$. Average mitochondrial light density intensities were normalized to pixel intensities of thin myofilament from the same image. We measured hundreds of mitochondria per heart, so we analyzed frequency distribution of mitochondrial optical density and area with density profile.

\section{Statistical analysis}

All continuous variables were presented as mean \pm standard deviation. For normally distribute data, the mean values of multiple groups were performed by analysis of variance (ANOVA) and LSD test. All categorical variables were presented as counts and percentage (\%). Fisher's exact test was used for categorical variables to determine differences between the groups. SPSS 25.0 (IBM, USA) was used for statistical analysis, and all statistical calculations followed a two-tailed test in which $p<0.05$ was considered statistically significant. Statistical diagrams were plotted by Graphpad Prism 7.0 (Graphpad Software, USA).

\section{Results}




\section{Clinical diagnosis, genetics and classification of AC patients.}

The diagnosis of AC patients was compliance with the 2010 International Task Force Criteria by clinical and pathological evaluation ${ }^{10}$. Between 2005 and 2018, 24 heart transplantation (HTx) patients (13 males) were recruited whose electron microscope samples were collected. The clinical characteristics of AC patients was shown as Fig.1. The precordial leads electrocardiogram (Fig.1A) showed a repolarization abnormality that was characteristic of AC, with negative T waves in leads $\mathrm{V} 1$ through $\mathrm{V} 5$, besides premature ventricular beats was also seen. The cardiac magnetic resonance imaging (CMR) and histopathology showed that right ventricle was dilated and the loss of right ventricular myocardium with the substitution of fibrous and fatty tissue. Each patient's diagnosis of AC is confirmed by pathology (Fig.1B-D). We identified the genetic background of these AC patients, 10 of 24 patients (26.7\%) carried desmosomal gene mutations (PKP2 (1), DSP (3), DSG2 (5), DSC2 (1)), 8 of 24 patients (33.3\%) was caused by non-desmosomal gene mutations (LMNA (2), PLN(3), DES (1), RYR2 (1) and CTNNA3 囚1ه), and the rest 6 patients did not carry any known gene mutations.

These 24 patients with AC were divided into DP group $(n=10)$ and DN group $(n=14)$. The detailed clinical characteristics were analyzed based on the two clusters (Table 1). The mean age of initial symptoms and HTx were similar between the two groups (DP vs DN, age of onset, $29.20 \pm 14.84$ yrs vs. $30.57 \pm 9.29 \mathrm{yrs}$, $\mathrm{p}=0.585$. Age of $\mathrm{Htx}, 37.30 \pm 15.81 \mathrm{yrs} v \mathrm{vs} .38 .43 \pm 11.91 \mathrm{yrs}, \mathrm{p}=0.843$ ). The two groups had basically the same symptoms, both in clinical symptoms and in the occurrence of arrhythmias. Patients in both groups developed palpitations (DP vs. DN, $80.00 \%$ vs. $71.43 \%, p=1.000$ ) and dyspnea (DP vs. DN, $70.00 \%$ vs. $85.71 \%, p=0.615)$ firstly, and half patients in either group had experienced symptoms of sustained ventricular tachycardia (DP vs. DN, $50.00 \%$ vs. $50.00 \%, p=1.000$ ). In terms of ultrasound heart morphology, the two groups of patients had similar left atrium diameters (DP vs. DN, $32.90 \pm 9.48 \mathrm{~mm}$ vs. $36.86 \pm 8.27 \mathrm{~mm}, \mathrm{p}=0.472$ ), left ventricular end-diastolic diameters (DP vs. DN, $50.40 \pm 12.78 \mathrm{~mm}$ vs. $54.14 \pm 12.01 \mathrm{~mm}, \mathrm{p}=0.471$ ) and right ventricular end-diastolic diameters (DP vs. DN, $43.90 \pm 14.36 \mathrm{~mm}$ vs. $38.64 \pm 10.50 \mathrm{~mm}, \mathrm{p}=0.310$ ). There was also no significant difference in left ventricular ejection fraction between the two groups (DP vs. DN, $42.20 \pm 19.41 \%$ vs. $35.50 \pm 12.88 \%, p=0.319$ ). In summary, the above results show that there is no obvious correlation between genetic background and clinical symptoms.

\section{Intercalated discs differences between left and right ventricle in AC and donor hearts}

To understand the ultrastructure differences between LV and RV, we compared the convolution index and three intercellular structures including $D$, gap junction (Gj), fascia adheres (FA). First, we compared the ultrastructural differences between LV and RV in normal donor hearts (Table 2). The D mean length $(0.17$ $\pm 0.01 \mu \mathrm{m}$ vs. $0.14 \pm 0.01 \mu \mathrm{m}, p=0.001)$ and $D$ percent length of intercalated disc $(10.82 \pm 3.12 \%$ vs. $6.75 \pm$ $1.11 \%, p=0.001)$ of LV is significantly higher than that of the RV, respectively. It was indicated that the intercellular connection of LV is more stable and robust. Next, we compared the ultrastructural differences between LV and RV in AC hearts, but no differences were found between LV and RV in AC patients (Table

2). It suggested that the LV and RV may suffer from varying degrees of intercalated disc remodeling in 
AC. Therefore, we proceeded to investigate the differences in the left ventricle between $A C$ and donor hearts, and the differences in the RV between $A C$ and donor hearts, respectively. The mean $D$ number per $10 \mu \mathrm{m}$ length ( $3.77 \pm 1.58$ per $10 \mu \mathrm{m}$ vs. $4.21 \pm 1.76$ per $10 \mu \mathrm{m}, \mathrm{p}=0.001)$ and $\mathrm{D}$ percent length of intercalated disc $(6.65 \pm 2.77 \%$ vs. $10.82 \pm 3.12 \%, p=0.001)$ was lower in LV of AC than in donor hearts. It is known that the hemodynamic pressure of the LV is significantly higher than that of the RV ${ }^{11}$. The high pressure in the LV may explain the loss of desmosomes in AC patients. Interestingly, we found that the mean Gj length was shorter in LV of AC than donor hearts $(0.21 \pm 0.13 \mu \mathrm{m}$ vs. $0.32 \pm 0.16 \mu \mathrm{m}, p=0.047)$. The shorter gap junctions in LV of AC may be associated with arrhythmias ${ }^{12}$. The differences between AC and donor hearts in RV that the mean $D$ length $(0.17 \pm 0.05 \mu \mathrm{m}$ vs. $0.14 \pm 0.01 \mu \mathrm{m}, p=0.002)$, the $D$ gap $(21.38 \pm 2.31 \mathrm{~nm}$ vs. $18.09 \pm 0.98 \mathrm{~nm}, \mathrm{p}=0.001)$ and the FA gap $(23.89 \pm 3.40 \mathrm{~nm}$ vs. $22.07 \pm 1.60 \mathrm{~nm}$, $\mathrm{p}=0.035$ ) were significantly higher in $\mathrm{AC}$ than in normal hearts, and were accordance with the previous report ${ }^{7}$. This confirmed that not only the RV intercalated disc structure had changed in AC, but also the LV of $A C$ patients had undergone intercalated disc remodeling, especially the changes of $D$ structure.

\section{Intercalated discs remodeling between DP group and DN group}

To investigate whether the desmosomal remodeling was a specific change in patients with desmosomal mutations, we compared the structural changes of desmosomes between DP group and DN group (Fig2 $A-C$ ). We found the density (the mean D number per $10 \mu \mathrm{m}$ ) and proportion (D percent length of intercalated disc) of desmosomes in DP and DN group were significantly less than that of normal group, respectively, but no differences were not significate between DP and DN group (DP vs. DN vs. Normal, density, $3.61 \pm 1.37$ vs. $4.10 \pm 1.75$ vs. $6.35 \pm 1.84$, $p=0.002$, proportion, $6.38 \pm 2.86 \%$ vs. $6.86 \pm 2.80 \%$ vs. $10.82 \pm 3.12 \%, p=0.003$, Fig. $2 D$ ). In the RV, we could see compensatory broadening and lengthening of Ds in both DP and DN groups (Fig3 A-C), the length and width of desmosomes in DP and DN group were significantly higher than that of normal group. Similarly, the above difference did not exist between the DP and DN group (DP vs. DN vs. Normal, length, $0.17 \pm 0.03 \mu \mathrm{m}$ vs. $0.18 \pm 0.06 \mu \mathrm{m}$ vs. $0.14 \pm 0.01 \mu \mathrm{m}$, $\mathrm{p}=0.009$, width, $20.94 \pm 0.77 \mathrm{~nm}$ vs. $21.63 \pm 2.84 \mathrm{~nm}$ vs. $18.09 \pm 0.98 \mathrm{~nm}, \mathrm{p}=0.001$, Fig. 3D)

In a word, no statistically significant differences were found between DP and DN group, the remodelling of the desmosome structure had no correlation with the mutation of the desmosome genes.

\section{Disintegrated $D$ in patients with no known mutation}

Among the AC patients in this study, there was 6 patients who didn't carry any known mutations, but they had a clear diagnosis of ACM. We compared the D structures characters of these patient (Fig. 4A-B) with that of normal people. Whether in the LV or the RV, the density and proportion of D were lower in these 6 patients than that in the normal group (Fig. 4C). The optical intensity of D showed a noticeable paleness in the both ventricles of ACM patients with no known mutation. Parts of the intercalated discs have become blurred, and cell junction proteins were diffusely distributed in the intercellular space and cytoplasm around the cell membrane. Although these patients had no known mutations, their desmosome structure had been destroyed to varying degrees. 


\section{The proportion of $D$ in $L V$ are positively correlated with ST segment time in AC patients}

To access the electrophysiological remodeling in relation to $D$ loss, the following parameters were measured by surface ECG, including RR interval time, R wave peak time, ST segment time, QT interval time, Sokolow-Lyon voltage (SV1 + RV5/V6), Cornell voltage (SV3 + RaVL). To calculate QTc from the uncorrected QT and heart rate, we followed the method as previously reported8. The relationship between D loss in both ventricles and 12-lead ECG parameters is shown in Table 3. We found no relationships between the proportion of D in RV and ECG parameters. Whereas, we find the proportion of D in LV are positively correlated with ST segment time, the fewer D, the shorter the ST segment time (Fig 5A). ST segment time is affected by heart rates (Fig $5 B$ ). To exclude the above difference was due to the difference in heart rates, we analyzed the correlation between RR interval time and the proportion of $D$ in $\mathrm{LV}$, and found no correlation between the two parameters (Fig $5 \mathrm{C}$ ). The above results indicated that $\mathrm{D}$ loss may cause abnormal repolarization of the action potential plateau phase in AC patients.

\section{Mitochondrial structure is not different between AC and donor hearts}

To investigate the mitochondrial morphological changes in AC hearts, we proceeded to examine ultrastructural differences between donor and AC heart mitochondria (Fig. 6A-B). We measured mitochondrion density, cross-sectional area for each mitochondrion, and quantified cristae density by using mean optical density (range: $0-2.708$ ), and we normalized them to myofilament optical density for each image. Because we measured hundreds of mitochondria per heart, we analyzed frequency distribution data with density profile. Fig $6 \mathrm{C}-\mathrm{F}$ showed the density profile of mitochondrion area and mean relative optical density among $\mathrm{AC}$ patients and normal control, respectively. There was also no statistical difference in mitochondrial area between donor and failing AC hearts in both ventricle (LV average mitochondrial area: $0.25 \pm 0.05 \mu \mathrm{m}^{2}$ vs. $0.30 \pm 0.03 \mu \mathrm{m}^{2}, \mathrm{p}=0.332$; RV average mitochondrial area: $0.34 \pm$ $0.07 \mu \mathrm{m}^{2}$ vs. $0.31 \pm 0.02 \mu \mathrm{m}^{2}, p=0.603$, Fig. $6 \mathrm{C}$-D). Mean relative mitochondrial optical intensities were $1.25 \pm 0.11$ for donor mitochondria compared with $1.37 \pm 0.09$ for failing AC mitochondria in left ventricle ( $p=0.764$; Fig. $6 E$ ), $1.24 \pm 0.09$ for donor mitochondria compared with $1.34 \pm 0.06$ for failing AC mitochondria in right ventricle $(p=0.658$; Fig. $6 F)$, which indicated no differences in cristae density and mitochondrial swelling in both ventricles. In addition, average mitochondrial density was not different between donor and failing AC hearts in both ventricles (LV average mitochondrial density: $38.18 \pm 3.21$ per $100 \mu \mathrm{m}^{2}$ vs. $41.88 \pm 3.01$ per $100 \mu \mathrm{m}^{2}, \mathrm{p}=0.464$; RV average mitochondrial density: $34.29 \pm 3.71$ per $100 \mu m^{2}$ vs. $34.99 \pm 3.24$ per $100 \mu m^{2}, p=0.893$, Fig. $\left.6 G-H\right)$.

\section{Discussion}

In the present study, we provided a comprehensive ultrastructural analysis in LV and RV cardiomyocytes of 24 AC. Detailed genetic screening and pathological examination were also performed on these 24 AC patients. According to the genetic background, they were classified into two different subtypes. We stated that no different ultrastructural $D$ alteration existed between DP and DN group. The D disintegration 
which indicated cardiomyocyte connections become loose were the common phenomenon in AC patients. The $\mathrm{D}$ disintegration may be related to work intensity of heart.

\section{Gradual loss of desmosomes during the progress of AC}

AC is considered as a cell-to-cell junction cardiomyopathy characterized by intercalated discs ultrastructural abnormalities consisting of decreased $D$ number and increased $D$ length, pale $D$ and abnormal small junctions, and intercellular gap widening in the RV ${ }^{7}$. Our results confirmed these previous findings of RV, and also showed that $\mathrm{D}$ remodeling were very obvious in the LV (Table 2). By comparing the ultrastructure of $D$ between $L V$ and RV in normal donor hearts, we found that the $D$ mean length and $D$ percent length of intercalated disc of LV is significantly higher than that of RV. It is indicted that LV need more stable and robust intercellular connection to meet the requirements of its high pressure. However, these differences were disappeared in AC patients (Table 2). The density and proportion of D decreased significantly in LV. This suggested a gradual loss of D during the progress of AC.

\section{Desmosome remodeling had no correlation with gene mutation}

In about $40-50 \%$ of patients, $A C$ is a genetic disease caused by a mutation of desmosomal gene. A minority of affected patients (20-30\%) have defective non-desmosomal genes. The rest proportion of patients have no known mutation with a phenotype of $\mathrm{AC}^{13}$. Therefore, we hypothesized that there may be some different changes of intercalated disc between DP and DN group. We found incomplete, disintegrating $\mathrm{D}$ structures in the both DP and DN patients compared with normal people. Especially in the LV where the pressure load is high, the density and proportion of complete D were less in both DP and DN patients compared to normal hearts, but the difference were not found between DP and DN group. Note that the length and width of $D$ in the RV was longer in AC than in normal hearts. This could be abnormal compensatory changes to stabilize intercellular connection, but the compensatory changes were no different between DP and DN group. The above results indicated that the D structure changes were independent of the $D$ gene mutation.

To further rule out the effects of non-desmosomal mutations on intercellular connections, we analyzed the $D$ structure of $A C$ patients without known gene mutation. In these $A C$ patients, the density and proportion of $\mathrm{D}$ both decreased in LV and RV compared with controls. These results suggested that desmosomal disruption was a common phenomenon in AC patients, and had no correlation with gene mutation. That may be the reason why anti-DSG2 antibodies were present in AC subjects regardless of whether an underlying mutation was identified, or which mutation was present ${ }^{14}$.

\section{The LV and RV showed different desmosome remodeling patterns in AC patients}

Under normal conditions, right-sided pressures are significantly lower than comparable left-sided pressures. RV isovolumic contraction time is shorter because RV systolic pressure rapidly exceeds the low pulmonary artery diastolic pressure ${ }^{15}$. The LV has about 1.9 times more work per gram of myocardium per stroke than the $\mathrm{RV}^{16}$. Therefore, comparing the ultrastructure of $\mathrm{D}$ in the LV and RV may help clarify 
the remodeling mode of $D$ under different work states. This could allow us to analyze the effect of exercise on the progress of $A C$ disease from the perspective of ultrastructure. In normal hearts, The $D$ mean length of LV was longer than RV $(0.17 \pm 0.01 \mu \mathrm{m}$ vs. $0.14 \pm 0.01 \mu \mathrm{m}, \mathrm{p}=0.001)$, and the $\mathrm{D}$ percent length of intercalated disc of LV was about 1.6 times that of RV $(10.82 \pm 3.12 \%$ vs. $6.75 \pm 1.11 \%$, $\mathrm{p}=0.001)$. It was indicated that $\mathrm{LV}$ did need more $\mathrm{D}$ structure to strengthen the connection between cardiomyocytes.

Our results showed that the $\mathrm{D}$ of LV were mainly manifested as a decrease in number and proportion during the disease course of AC. This suggested that the $\mathrm{D}$ of $\mathrm{LV}$ became disintegrated under high work pressure. However, the D of RV were mainly manifested as compensatory lengthening and broadening, which indicated that the $\mathrm{D}$ of RV could maintain basic fastener shape under the condition of low work, so the density and proportion of $\mathrm{D}$ in RV did not decrease significantly. This partly explains why competitive sport was associated with a two-fold increased risk of ventricular tachyarrhythmias/death, and earlier presentation of symptoms in AC patients ${ }^{17}$. Increased work intensity of heart may accelerate the desmosome remodeling or disintegration, but further sophisticated hemodynamic studies are needed to prove the theory.

\section{The D loss in LV caused ST segment shortening}

The ST segment corresponds to the plateau phase of the ventricular transmembrane action potential ${ }^{18}$. Cardiomyocytes have a longer refractory period than other muscle cells given the long plateau from slow $\mathrm{Ca}^{2+}$ channels. Our results showed that the proportion of $\mathrm{D}$ in LV was positively correlated with ST segment time. This suggested that the damage of $D$ may shorten the refractory period. Refractory period shortening may increase the incidence of ventricular arrhythmia ${ }^{19}$. Our results established the relationship between $D$ remodeling and electrophysiological remodeling, which provided directions for future mechanism research.

\section{Normal mitochondrial function incardiomyocytes derived from AC patients}

The heart is one of the most mitochondria-enriched organs. Mitochondrial oxidative phosphorylation generates up to $90 \%$ of ATP, required for cardiomyocytes contraction, and the mitochondria occupy almost $30 \%$ of cardiomyocyte volume ${ }^{20}$. Mitochondria have emerged as critical integrators of energy production, ROS generation, $\mathrm{Ca}^{2+}$ handling and multiple signaling and cell death pathways ${ }^{21}$. To avoid mitochondrial injury, cardiomyocytes develop coordination mechanism that maintain the overall mitochondrial morphology and function health through mitochondrial fusion, fission and autophagy. To investigate the mitochondrial function in residual cardiomyocytes of $A C$, we examined the mitochondrial ultrastructural differences between donor and AC heart mitochondria. Average mitochondrial density was similar between donor and AC hearts in both ventricles. In addition, mean relative mitochondrial optical intensities were also similar in both ventricles between AC and donor heart, which indicated no differences in cristae density and mitochondrial swelling. From the view of mitochondrial morphology alone, the mitochondria of the residual cardiomyocytes maintained normal functions. Previous study also 
showed that mitochondrial structure and function were not different between nonfailing donor and endstage failing human hearts ${ }^{9}$. We conducted 24 AC hearts and 10 donor hearts, which is more convincing than previous studies. Our investigation provided stronger evidence for lack of mitochondria dysfunction from residual cardiomyocytes. It is known that the ventricular muscles are largely replaced by fibrofatty tissue in RV some involved with LV of AC patients. Even if the remaining cardiomyocytes have an adequate energy supply, they cannot maintain the normal cardiac systolic function.

This study has limitations and needs to be further improved in future studies. Firstly, this is a study based on AC patients undergoing HTx, it cannot reflect the whole continuous process of $D$ remodeling. Secondly, due to the limitation of electron microscope study, only a limited number of cardiomyocytes can be observed, therefore, the quantitative data may have measurement error, further large sample size studies are needed to reduce the bias.

\section{Conclusions}

Our study provided a combined analysis of genotype and ultrastructure of $A C$ patients. The $D$ disintegration were present in AC subjects regardless of whether a pathogenic mutation was identified, or which type of mutation was present. In the course of AC disease, the LV and RV had different remodeling patterns. The $D$ of LV mainly showed a decrease in density and proportion, but the $D$ of RV were mainly manifested as compensatory widening and lengthening. From the perspective of ultrastructure, we concluded that increased output power of heart may accelerate the desmosome remodeling or disintegration. And we found D loss in LV may cause ST segment shortening, established the relationship between $\mathrm{D}$ remodeling and electrophysiological remodeling, ST segment shortening may serve as a marker of disease progression.

\section{Abbreviations}

AC Arrhythmogenic cardiomyopathy

CMR Cardiac magnetic resonance imaging

D Desmosome

DP desmosome gene mutation positive

DN desmosome gene mutation negative

ECG electrocardiography

FA Fascia adheres

Gj Gap junction 
HTx Heart transplant

LV Left ventricle

QTc corrected QT

RV Right ventricle

\section{Declarations}

\section{Ethics approval and consent to participate}

The collection of tissue samples and the clinical and pathological information was approved by Fuwai Hospital. All patients provided written informed consent to participate in the study, and the research conformed with the principles of the Declaration of Helsinki.

\section{Consent for publication}

Not applicable.

\section{Availability of data and materials}

All data generated or analysed during this study are included in this published article [and its supplementary information files].

\section{Competing interests}

The authors declare that they have no competing interests.

\section{Funding}

This work was supported by Shanghai Municipal Science and Technology Major Project (Grant No. 2017SHZDZX01) and PUMC Youth Fund (2016-XHQN03) and the Fundamental Research Funds for the Central Universities, Innovation Fund for Medical Sciences (CIFMS, 2016-I2M-1-015) and National Natural Science Foundation of China (Grant No. 81670376).

\section{Author's contributions}

SSH and JPS designed and supervised the study. YC, XMH and YQH performed the experiments. XC, WDL, XXF, MHT, SC participated in heart sample collection and processing. YC and XMH wrote the manuscript draft. HS and SJ revised the manuscript. All authors read and approved the manuscript.

\section{Authors' information}

Shengshou Hu, Email: fwhushengshou@163.com 
Jiangping Song, Email: fwsongjiangping@126.com

\section{References}

1. Corrado D, Link MS and Calkins H. Arrhythmogenic Right Ventricular Cardiomyopathy. The New England journal of medicine. 2017;376:61-72.

2. Corrado D, Basso C and Judge DP. Arrhythmogenic Cardiomyopathy. Circulation research. 2017;121:784-802.

3. van Hengel J, Calore M, Bauce B, Dazzo E, Mazzotti E, De Bortoli M, Lorenzon A, Li Mura IE, Beffagna G, Rigato I, Vleeschouwers M, Tyberghein K, Hulpiau P, van Hamme E, Zaglia T, Corrado D, Basso C, Thiene G, Daliento L, Nava A, van Roy F and Rampazzo A. Mutations in the area composita protein alphaT-catenin are associated with arrhythmogenic right ventricular cardiomyopathy. European heart journal. 2013;34:201-10.

4. Turkowski KL, Tester DJ, Bos JM, Haugaa KH and Ackerman MJ. Whole exome sequencing with genomic triangulation implicates $\mathrm{CDH} 2$-encoded $\mathrm{N}$-cadherin as a novel pathogenic substrate for arrhythmogenic cardiomyopathy. Congenital heart disease. 2017;12:226-235.

5. Mayosi BM, Fish M, Shaboodien G, Mastantuono E, Kraus S, Wieland T, Kotta MC, Chin A, Laing N, Ntusi NB, Chong M, Horsfall C, Pimstone SN, Gentilini D, Parati G, Strom TM, Meitinger T, Pare G, Schwartz PJ and Crotti L. Identification of Cadherin 2 (CDH2) Mutations in Arrhythmogenic Right Ventricular Cardiomyopathy. Circulation Cardiovascular genetics. 2017;10.

6. Bhonsale A, Groeneweg JA, James CA, Dooijes D, Tichnell C, Jongbloed JD, Murray B, te Riele AS, van den Berg MP, Bikker $\mathrm{H}$, Atsma DE, de Groot NM, Houweling AC, van der Heijden JF, Russell SD, Doevendans PA, van Veen TA, Tandri H, Wilde AA, Judge DP, van Tintelen JP, Calkins H and Hauer RN. Impact of genotype on clinical course in arrhythmogenic right ventricular dysplasia/cardiomyopathyassociated mutation carriers. European heart journal. 2015;36:847-55.

7. Basso C, Czarnowska E, Della Barbera M, Bauce B, Beffagna G, Wlodarska EK, Pilichou K, Ramondo A, Lorenzon A, Wozniek O, Corrado D, Daliento L, Danieli GA, Valente M, Nava A, Thiene G and Rampazzo A. Ultrastructural evidence of intercalated disc remodelling in arrhythmogenic right ventricular cardiomyopathy: an electron microscopy investigation on endomyocardial biopsies. European heart journal. 2006;27:1847-54.

8. Dash A, Torado C, Paw N, Fan D, Pezeshkian N and Srivatsa U. QT correction in atrial fibrillation Measurement revisited. J Electrocardiol. 2019;56:70-76.

9. Holzem KM, Vinnakota KC, Ravikumar VK, Madden EJ, Ewald GA, Dikranian K, Beard DA and Efimov IR. Mitochondrial structure and function are not different between nonfailing donor and end-stage failing human hearts. FASEB journal : official publication of the Federation of American Societies for Experimental Biology. 2016;30:2698-707.

10. Marcus FI, McKenna WJ, Sherrill D, Basso C, Bauce B, Bluemke DA, Calkins H, Corrado D, Cox MG, Daubert JP, Fontaine G, Gear K, Hauer R, Nava A, Picard MH, Protonotarios N, Saffitz JE, Sanborn DM, Steinberg JS, Tandri H, Thiene G, Towbin JA, Tsatsopoulou A, Wichter T and Zareba W. Diagnosis of 
arrhythmogenic right ventricular cardiomyopathy/dysplasia: proposed modification of the Task Force Criteria. European heart journal. 2010;31:806-14.

11. Sanz J, Sanchez-Quintana D, Bossone E, Bogaard HJ and Naeije R. Anatomy, Function, and Dysfunction of the Right Ventricle: JACC State-of-the-Art Review. Journal of the American College of Cardiology. 2019;73:1463-1482.

12. Severs NJ, Bruce AF, Dupont E and Rothery S. Remodelling of gap junctions and connexin expression in diseased myocardium. Cardiovascular research. 2008;80:9-19.

13. Corrado D, van Tintelen PJ, McKenna WJ, Hauer RNW, Anastastakis A, Asimaki A, Basso C, Bauce B, Brunckhorst C, Bucciarelli-Ducci C, Duru F, Elliott P, Hamilton RM, Haugaa KH, James CA, Judge D, Link MS, Marchlinski FE, Mazzanti A, Mestroni L, Pantazis A, Pelliccia A, Marra MP, Pilichou K, Platonov PGA, Protonotarios A, Rampazzo A, Saffitz JE, Saguner AM, Schmied C, Sharma S, Tandri H, Te Riele A, Thiene G, Tsatsopoulou A, Zareba W, Zorzi A, Wichter T, Marcus Fl and Calkins H. Arrhythmogenic right ventricular cardiomyopathy: evaluation of the current diagnostic criteria and differential diagnosis. European heart journal. 2020;41:1414-1429.

14. Chatterjee D, Fatah M, Akdis D, Spears DA, Koopmann TT, Mittal K, Rafiq MA, Cattanach BM, Zhao Q, Healey JS, Ackerman MJ, Bos JM, Sun Y, Maynes JT, Brunckhorst C, Medeiros-Domingo A, Duru F, Saguner AM and Hamilton RM. An autoantibody identifies arrhythmogenic right ventricular cardiomyopathy and participates in its pathogenesis. European heart journal. 2018;39:3932-3944.

15. Dell'Italia LJ and Walsh RA. Acute determinants of the hangout interval in the pulmonary circulation. American heart journal. 1988;116:1289-97.

16. Haddad F, Hunt SA, Rosenthal DN and Murphy DJ. Right ventricular function in cardiovascular disease, part l: Anatomy, physiology, aging, and functional assessment of the right ventricle. Circulation. 2008;117:1436-48.

17. Ruwald AC, Marcus F, Estes NA, 3rd, Link M, McNitt S, Polonsky B, Calkins H, Towbin JA, Moss AJ and Zareba W. Association of competitive and recreational sport participation with cardiac events in patients with arrhythmogenic right ventricular cardiomyopathy: results from the North American multidisciplinary study of arrhythmogenic right ventricular cardiomyopathy. European heart journal. 2015;36:1735-43.

18. Rautaharju PM, Surawicz B, Gettes LS, Bailey JJ, Childers R, Deal BJ, Gorgels A, Hancock EW, Josephson M, Kligfield P, Kors JA, Macfarlane P, Mason JW, Mirvis DM, Okin P, Pahlm O, van Herpen $\mathrm{G}$, Wagner GS and Wellens H. AHA/ACCF/HRS recommendations for the standardization and interpretation of the electrocardiogram: part IV: the ST segment, T and U waves, and the QT interval: a scientific statement from the American Heart Association Electrocardiography and Arrhythmias Committee, Council on Clinical Cardiology; the American College of Cardiology Foundation; and the Heart Rhythm Society: endorsed by the International Society for Computerized Electrocardiology. Circulation. 2009;119:e241-50.

19. Schmitt N, Grunnet M and Olesen SP. Cardiac potassium channel subtypes: new roles in repolarization and arrhythmia. Physiol Rev. 2014;94:609-53. 
20. Vasquez-Trincado C, Garcia-Carvajal I, Pennanen C, Parra V, Hill JA, Rothermel BA and Lavandero S. Mitochondrial dynamics, mitophagy and cardiovascular disease. The Journal of physiology. 2016;594:509-25.

21. Marin-Garcia $\mathrm{J}$ and Akhmedov AT. Mitochondrial dynamics and cell death in heart failure. Heart failure reviews. 2016;21:123-36.

\section{Tables}


Table 1. The clinical information between DP and DN group

ariables General $(n=24) \quad$ DP group $(n=10) \quad$ DN group $(n=14) \quad$ P-value

Characteristics

Age of onset

$37.96 \pm 13.35$

$29.20 \pm 14.84$

$30.57 \pm 9.29$

0.585

Age of $\mathrm{HTx}$

$30.00 \pm 11.64$

$37.30 \pm 15.81$

$38.43 \pm 11.91$

0.843

Male, n (\%)

13(54.17)

$7(70.00 \%)$

$6(42.86 \%)$

0.697

Height (cm)

$168.83 \pm 6.60$

$170.40 \pm 6.64$

$167.71 \pm 6.58$

0.337

Weight $(\mathrm{kg})$

$61.13 \pm 11.70$

$59.44 \pm 7.91$

$62.33 \pm 13.97$

0.931

$\mathrm{BM} \varangle \mathrm{kg} / \mathrm{m}^{2} \square$

$21.36 \pm 3.41$

$20.43 \pm 2.10$

$22.02 \pm 4.05$

0.224

\section{Symptoms and history}

Dyspnea

Palpitation

Syncope, n (\%)

Family history, n (\%)

\section{NYHA}

II, n (\%)

III, n (\%)

IV, n (\%)

\section{Arrhythmias}

Sustained VT, n (\%)

fVE, n (\%)

Atrial fibrillation, $\mathrm{n}(\%)$

Echocardiography

LA diameter $(\mathrm{mm})$

LVEDD (mm)

$\operatorname{LVEF}(\%)$

IVS (mm)

$\operatorname{RVEDD}(\mathrm{mm})$

$\mathrm{BMI}$, body mass index; fVE, frequent ventricular extrasystole; LA, left atria; LVEDD, left ventricular enddiastolic diameter; LVEF, left ventricular ejection fraction; HTx, Heart transplantation; IVS, 
interventricular septum; RVEDD, right ventricular end-diastolic diameter; VT, ventricular tachycardia.

Table 2. Intercalated discs differences between left and right ventricle in AC and donor hearts $\begin{array}{lllllllll}\text { Intercalated disc } & \text { AC } & \text { AC } & \text { Donor } & \text { Donor } & \text { AC LV } & \text { Donor LV } & \text { AC LV } & \text { AC RV } \\ & \text { LV } & \text { RV } & \text { LV } & \text { RV } & \text { VS AC } & \text { Vs Donor } & \text { Vs } & \text { Vs } \\ & & & & \text { RV } & \text { RV } & \begin{array}{l}\text { Donor } \\ \text { Donor } \\ \text { LV }\end{array} & & \\ & & & & & & & & \end{array}$

$\begin{array}{lllllllll}\text { Convolution index } & 2.32 & 2.27 & 2.34 & 2.51 & 0.712 & 0.912 & 0.950 & 0.230\end{array}$

$\begin{array}{llll}0.48 & 0.56 & 0.80 & 0.46\end{array}$

\begin{tabular}{|c|c|c|c|c|c|c|c|c|}
\hline D mean length $(\mu \mathrm{m})$ & $\begin{array}{l}0.17 \\
\pm \\
0.03\end{array}$ & $\begin{array}{l}0.17 \\
\pm \\
0.05\end{array}$ & $\begin{array}{l}0.17 \\
\pm \\
0.02\end{array}$ & $\begin{array}{l}0.14 \\
\pm \\
0.01\end{array}$ & 0.555 & 0.001 & 0.923 & 0.002 \\
\hline $\begin{array}{l}\mathrm{n}, \mathrm{D} / 10 \mu \mathrm{m} \text { unit } \\
\text { length }\end{array}$ & $\begin{array}{l}3.88 \\
\pm \\
1.58\end{array}$ & $\begin{array}{l}4.21 \\
\pm \\
1.76\end{array}$ & $\begin{array}{l}6.35 \\
\pm \\
1.83\end{array}$ & $\begin{array}{l}5.01 \\
\pm \\
0.86\end{array}$ & 0.519 & 0.052 & 0.001 & 0.183 \\
\hline
\end{tabular}

$\begin{array}{lllllllll}\begin{array}{l}\text { D percent length of } \\ \text { intercalated disc }\end{array} & 6.65 & 6.93 & 10.82 & 6.75 & 0.729 & \mathbf{0 . 0 0 1} & \mathbf{0 . 0 0 1} & 0.779 \\ (\%) & \left.\frac{ \pm}{2}\right) & \frac{ \pm}{2.67} & \frac{ \pm}{3.12} & \frac{ \pm}{1.11} & & & & \end{array}$

\begin{tabular}{|c|c|c|c|c|c|c|c|}
\hline $\begin{array}{l}\text { Gj mean length } \\
(\mu \mathrm{m})\end{array}$ & $\begin{array}{l}0.21 \\
\pm \\
0.13\end{array}$ & $\begin{array}{l}0.19 \\
\pm \\
0.11\end{array}$ & $\begin{array}{l}0.32 \\
\pm \\
0.16\end{array}$ & $\begin{array}{l}0.28 \\
\pm \\
0.10\end{array}$ & 0.665 & 0.531 & 0.047 \\
\hline
\end{tabular}

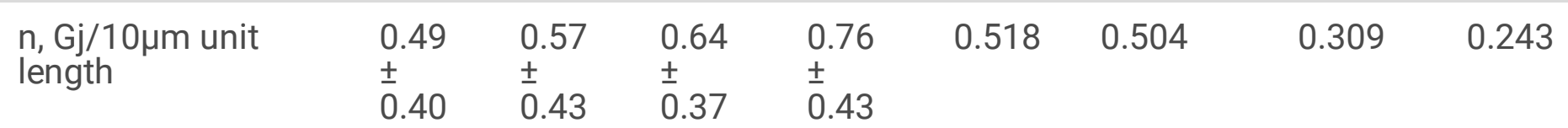

$\begin{array}{lllllllll}\text { Gj percent length of } & 1.25 & 1.36 & 1.83 & 2.24 & 0.746 & 0.971 & 0.154 & 0.204 \\ \text { intercalated disc } & \pm & \pm & \pm & \pm & & & & \\ (\%) & 1.11 & 1.07 & 0.90 & 1.93 & & & & \end{array}$

\begin{tabular}{|c|c|c|c|c|c|c|c|c|}
\hline D mean gap (nm) & $\begin{array}{l}22.15 \\
\pm \\
2.84\end{array}$ & $\begin{array}{l}21.38 \\
\pm \\
2.31\end{array}$ & $\begin{array}{l}21.71 \\
\pm \\
2.29\end{array}$ & $\begin{array}{l}18.09 \\
\pm \\
0.98\end{array}$ & 0.324 & 0.001 & 0.666 & 0.001 \\
\hline FA mean gap (nm) & $\begin{array}{l}26.98 \\
\pm \\
6.39\end{array}$ & $\begin{array}{l}23.89 \\
\pm \\
3.40\end{array}$ & $\begin{array}{l}26.05 \\
\pm 6,96\end{array}$ & $\begin{array}{l}22.07 \\
\pm \\
1.60\end{array}$ & 0.073 & 0.063 & 0.451 & 0.035 \\
\hline
\end{tabular}

D, Desmosome; Gj, Gap junction; FA, Fascia adherens. 


\begin{tabular}{|c|c|c|c|}
\hline & ECG parameters & $\begin{array}{l}\text { Pearson Correlation } \\
\text { Coefficient }\end{array}$ & $\begin{array}{l}\mathrm{P}- \\
\text { value }\end{array}$ \\
\hline \multirow{6}{*}{$\begin{array}{l}\text { D percent length of intercalated disc } \\
\text { in LV }\end{array}$} & RR interval time & 0.462 & 0.072 \\
\hline & $\mathrm{R}$ wave peak time & -0.501 & 0.051 \\
\hline & ST segment time & 0.726 & 0.001 \\
\hline & QTC & 0.142 & 0.599 \\
\hline & $\begin{array}{l}\text { Sokolow-Lyon } \\
\text { voltage }\end{array}$ & 0.027 & 0.921 \\
\hline & Cornell voltage & 0.180 & 0.505 \\
\hline \multirow{6}{*}{$\begin{array}{l}\text { D percent length of intercalated disc } \\
\text { in RV }\end{array}$} & RR interval time & 0.110 & 0.708 \\
\hline & $\mathrm{R}$ wave peak time & -0.338 & 0.237 \\
\hline & ST segment time & 0.493 & 0.073 \\
\hline & QTC & 0.338 & 0.238 \\
\hline & $\begin{array}{l}\text { Sokolow-Lyon } \\
\text { voltage }\end{array}$ & 0.211 & 0.469 \\
\hline & Cornell voltage & 0.273 & 0.344 \\
\hline
\end{tabular}

Figures 
A

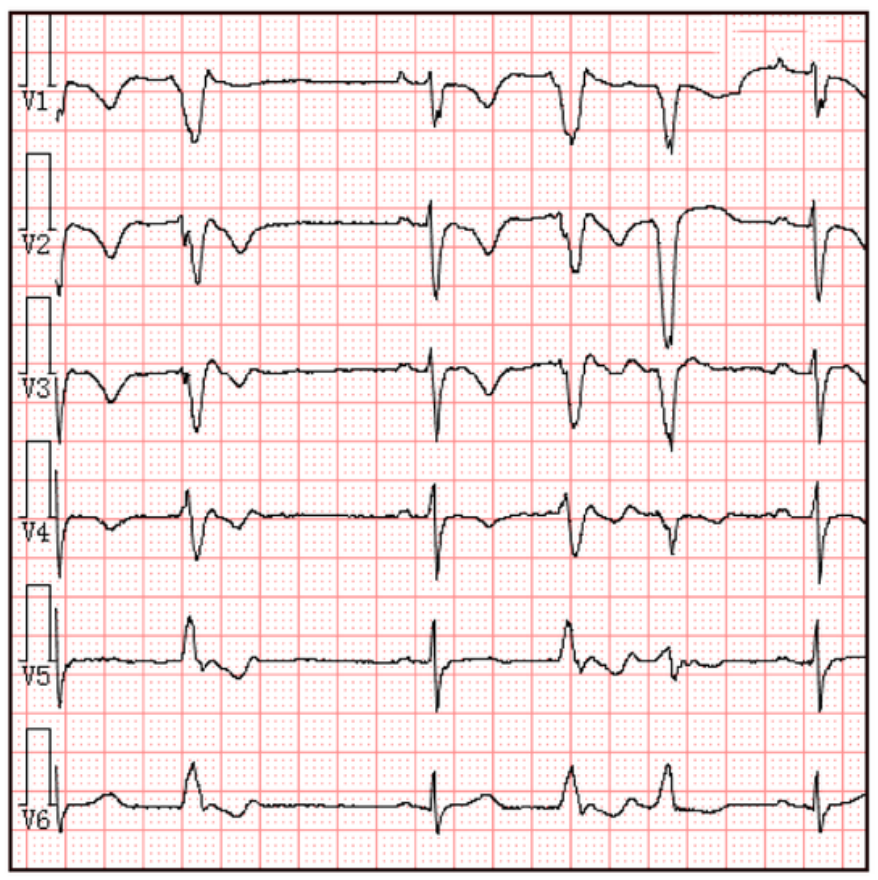

C

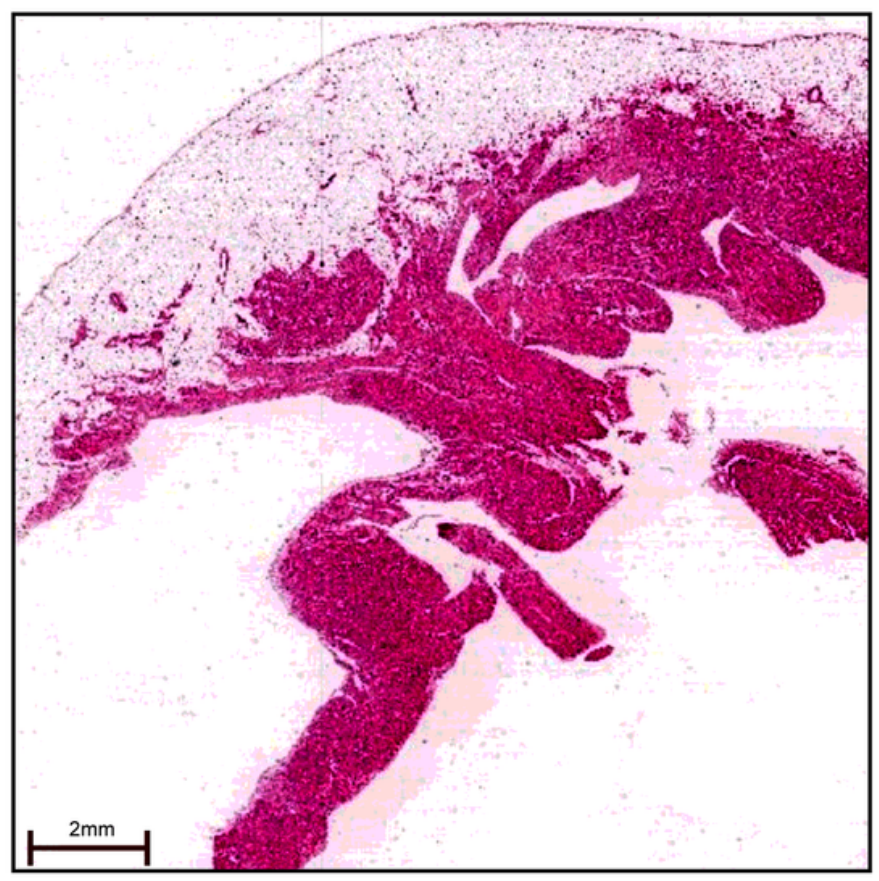

B

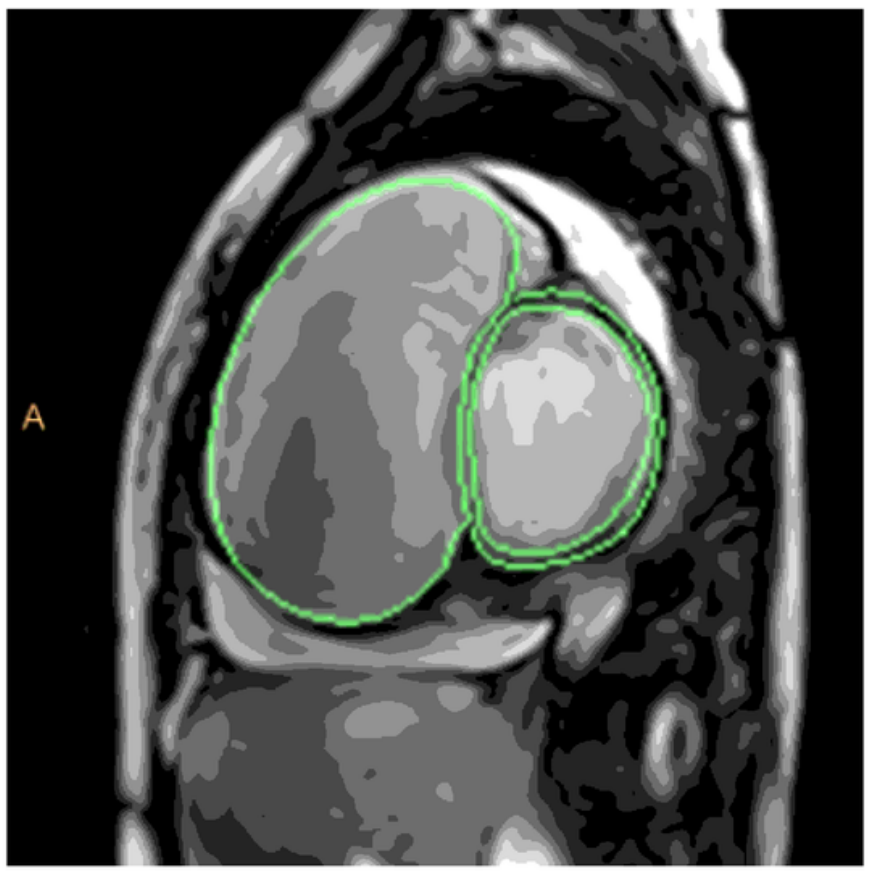

$D$

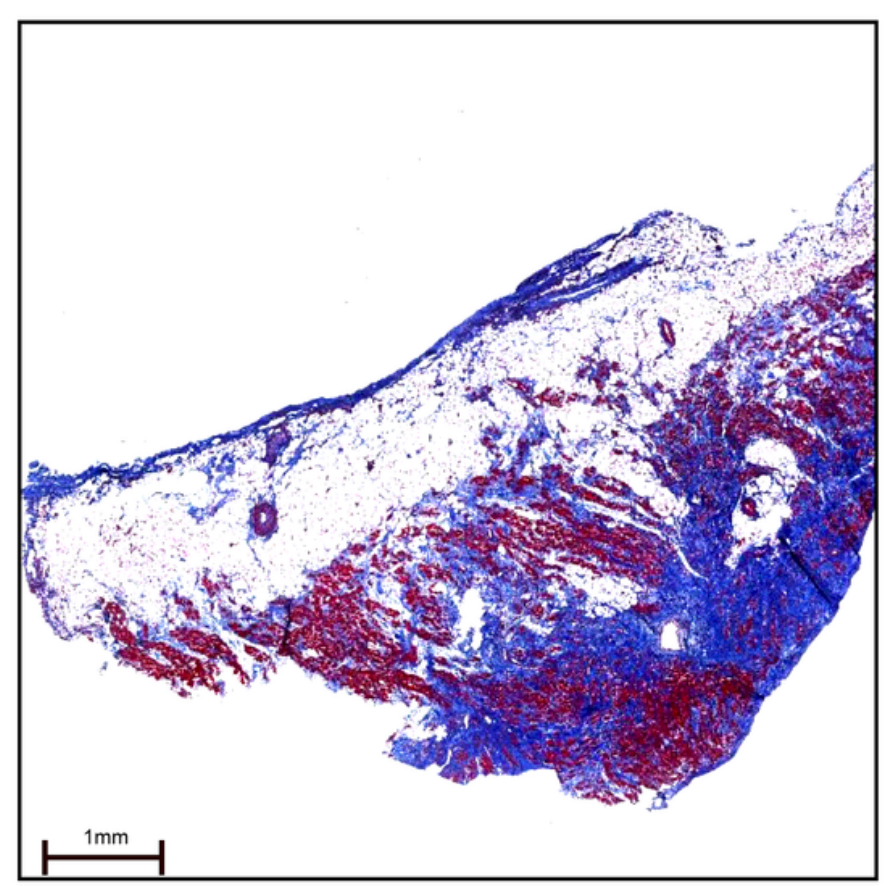

Figure 1

The clinical features of AC: a. Electrocardiograms; b. Cardiac Magnetic Resonance Imaging (CMR) of AC patients (short-axis); c. HE staining; d. Masson staining. 
A

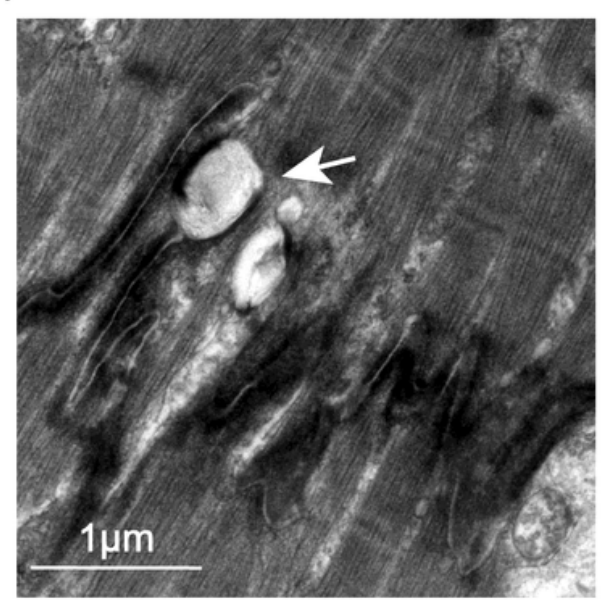

B

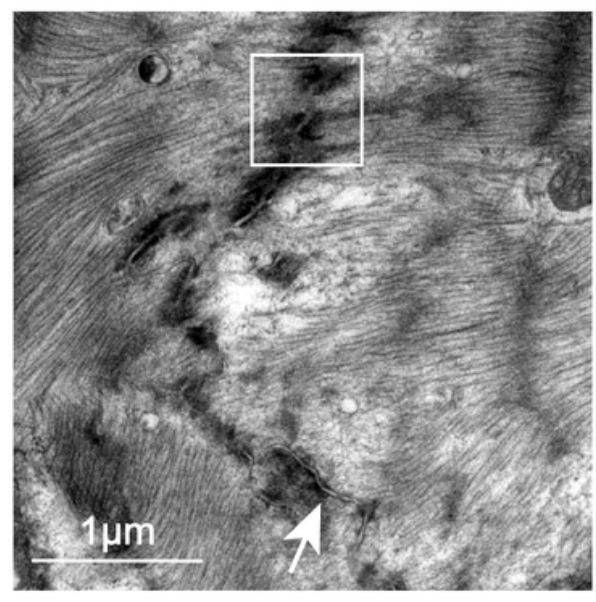

C

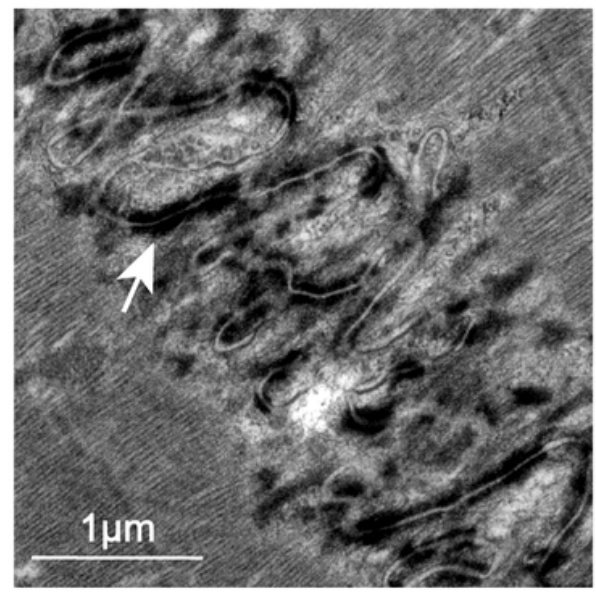

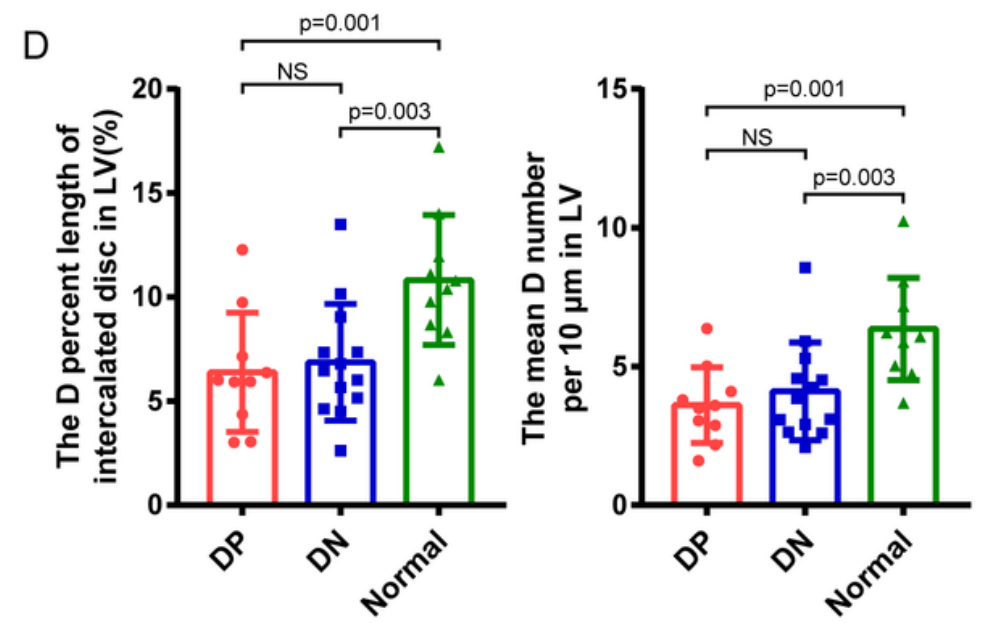
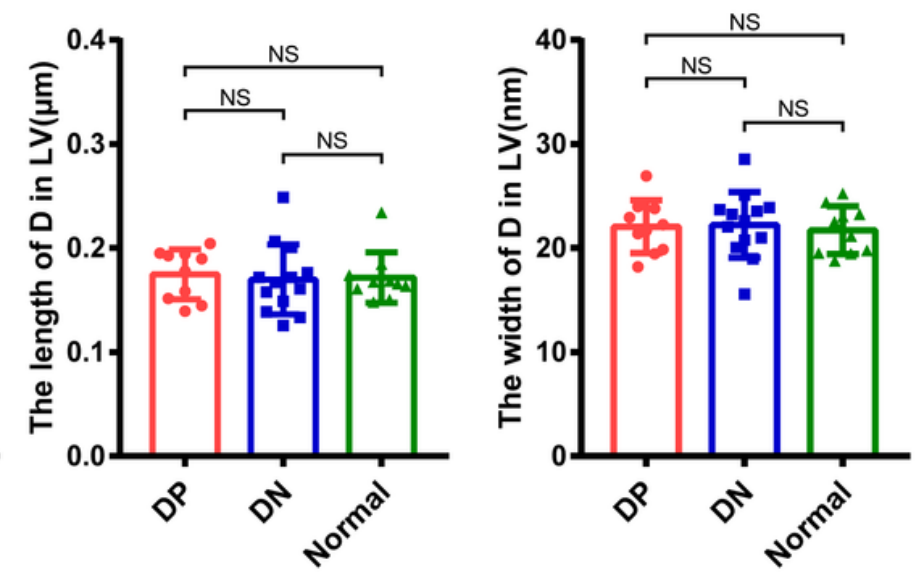

Figure 2

The ultrastructural features of D in LV: a. DP group, disintegration of D (arrowheads); b. DN group, pale $D$ (arrowhead) and diffusely distributed connexins (white box) $c$. The ultrastructural features of $D$ in normal donor hearts; $d$. Comparison of proportion, density, width and length of $D$ between three groups. Magnification: X30000. 
A

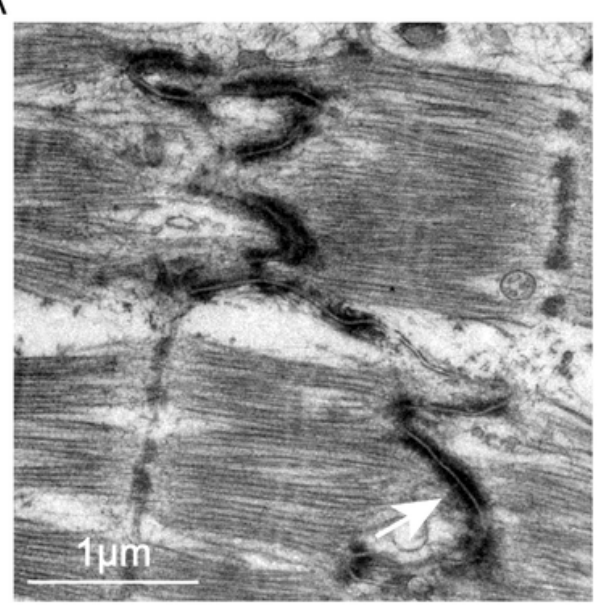

B

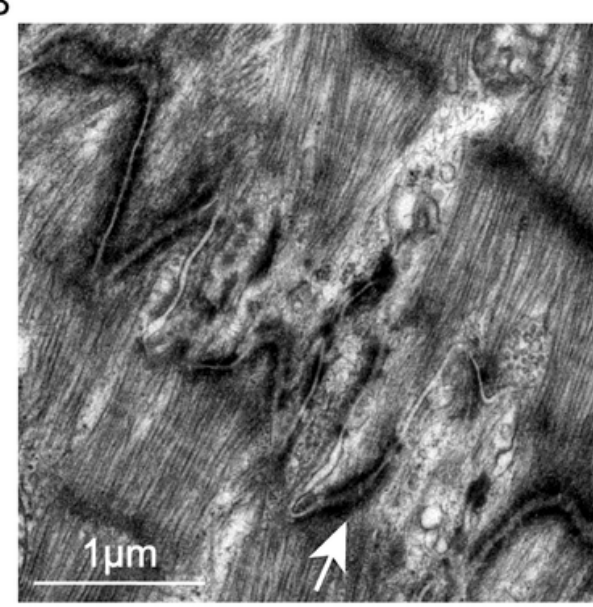

C

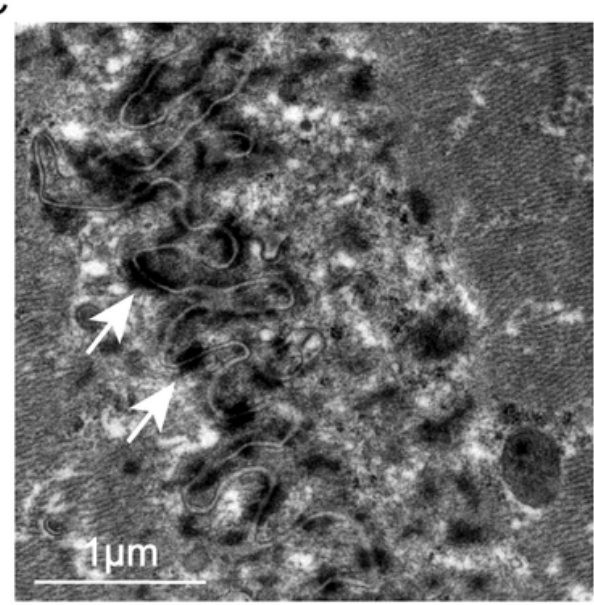

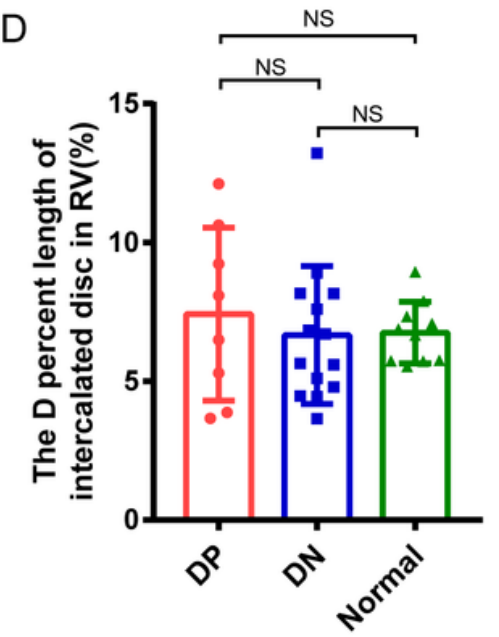
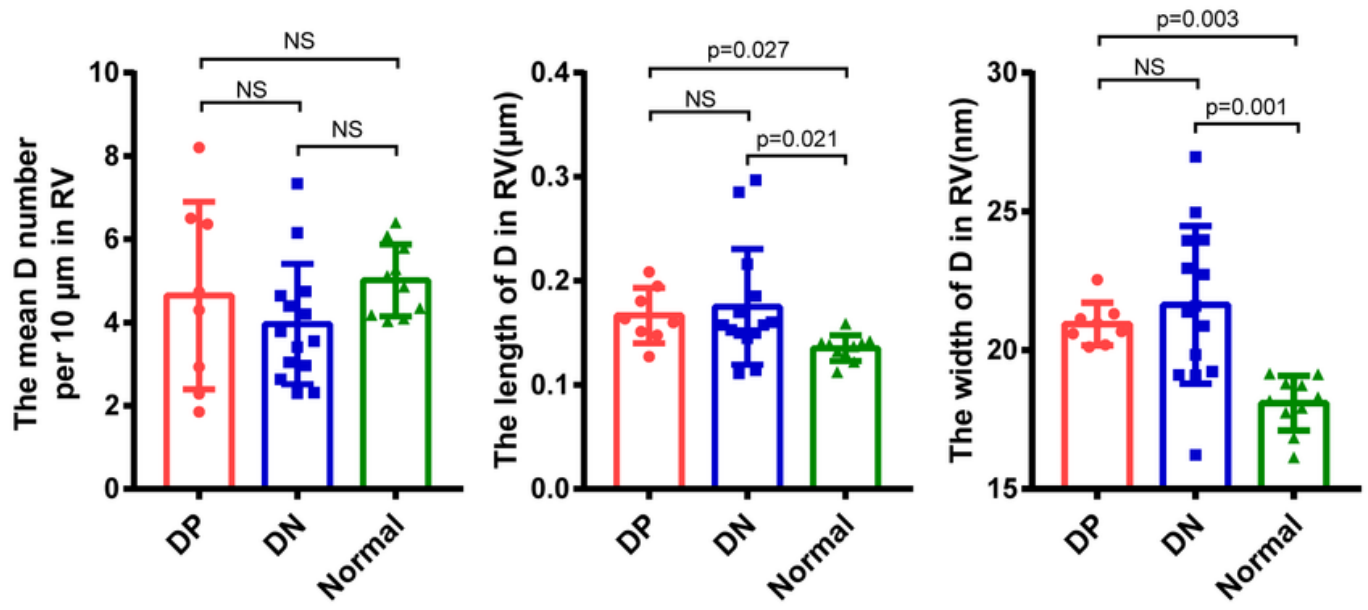

Figure 3

The ultrastructural features of D in RV: a. DP group, compensatory lengthening (arrowhead); b. DN group, compensatory broadening (arrowhead); c. The ultrastructural features of D in normal donor hearts; $d$. Comparison of proportion, density, width and length of D between three groups. Magnification: X30000. 
A

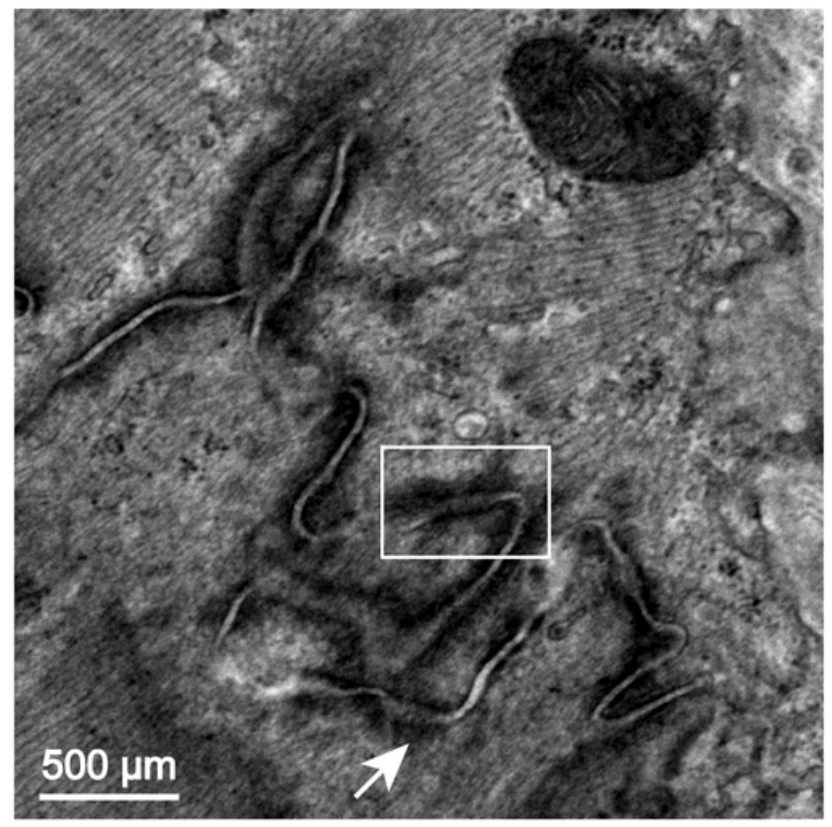

C

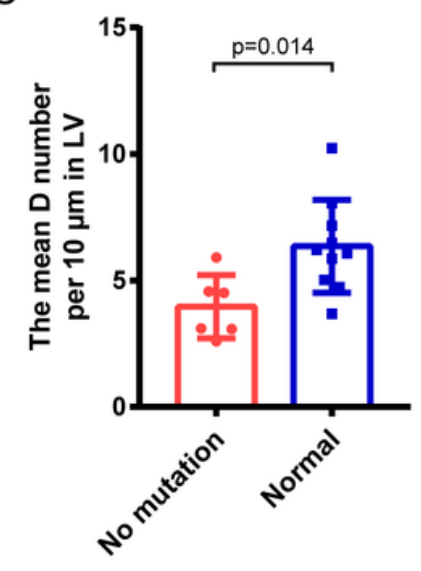

B

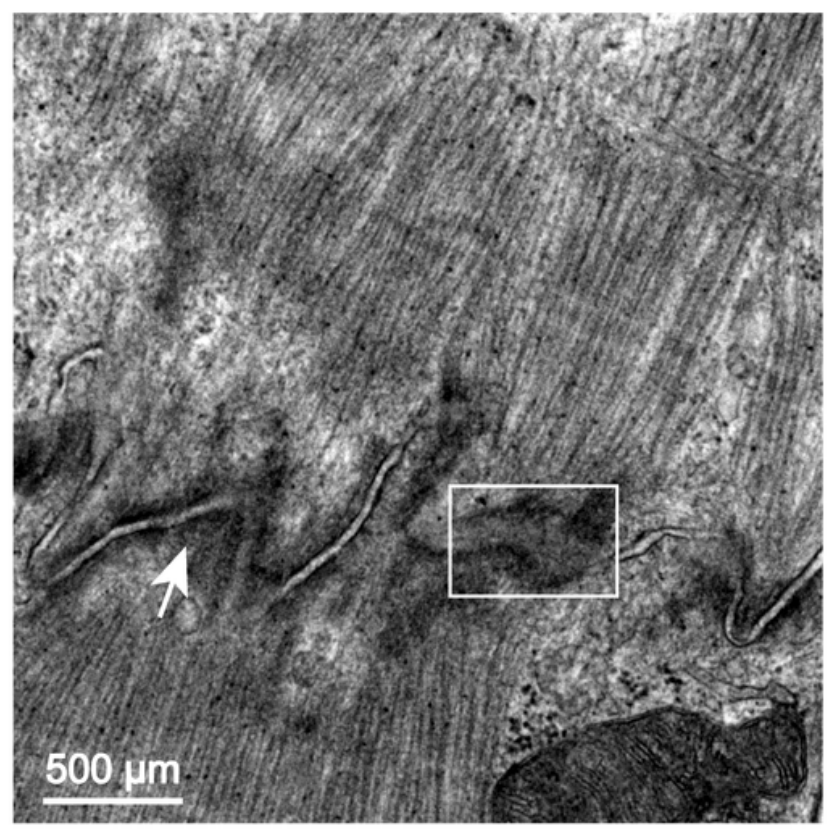

D

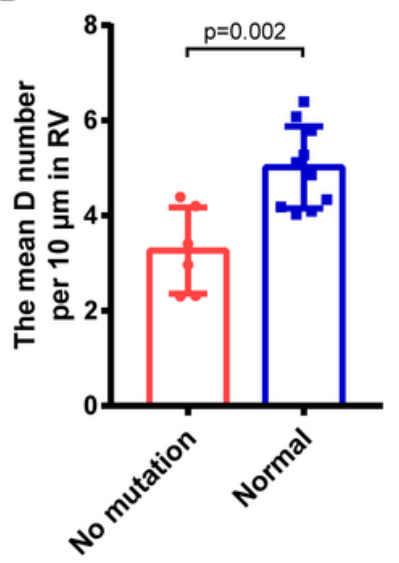

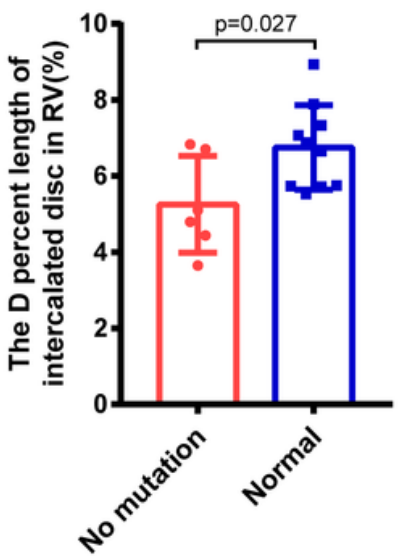

\section{Figure 4}

The intercalated discs remodeling in AC patient without known mutation: a. The intercalated discs of LV, loose $\mathrm{D}$ (white box) and pale and bulgy $\mathrm{D}$ (arrowheads); $\mathrm{b}$. The intercalated discs of RV, discontinuous and pale D (arrowheads), and blurred cell connections (white box). c. Comparison of proportion, density of $D$ in LV between AC patients without known mutation and normal people; $d$. Comparison of proportion, density of $\mathrm{D}$ in RV between AC patients without known mutation and normal people. Magnification: $\mathrm{X} 30000$. 

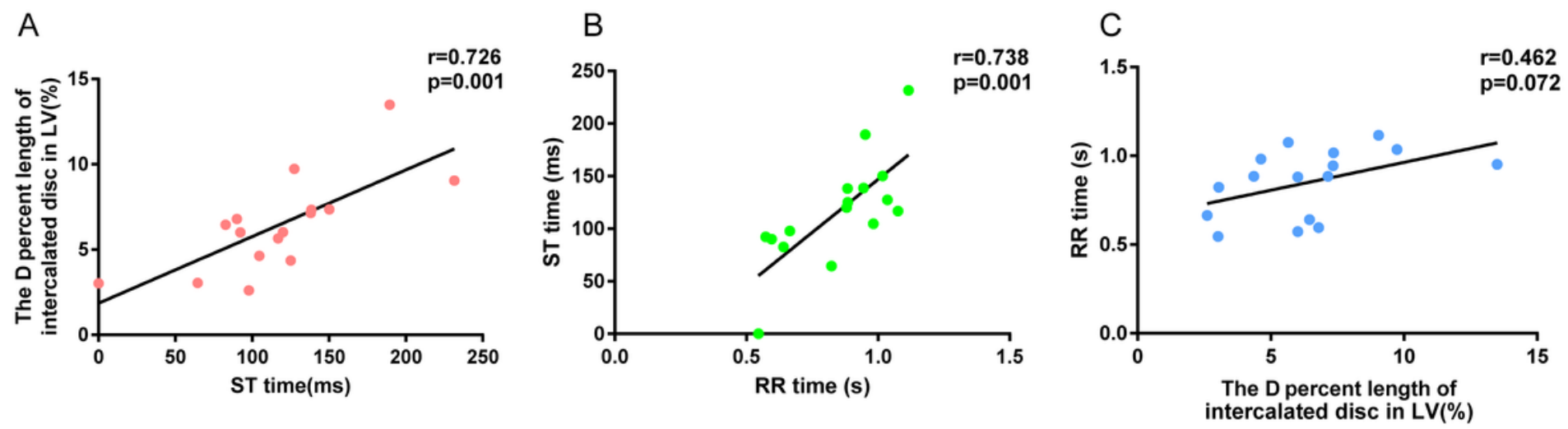

Figure 5

The D loss in LV may cause ST segment shortening: a. The proportion of D in LV was positively correlated with ST segment time. b. ST segment time was positively correlated with RR interval time. c. No correlation was found between RR interval time and the proportion of D in LV. 
A

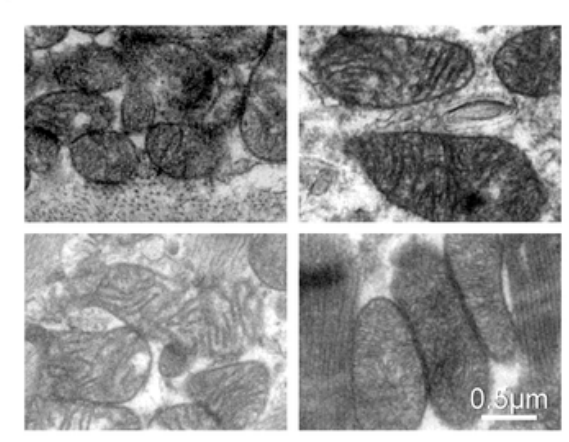

B

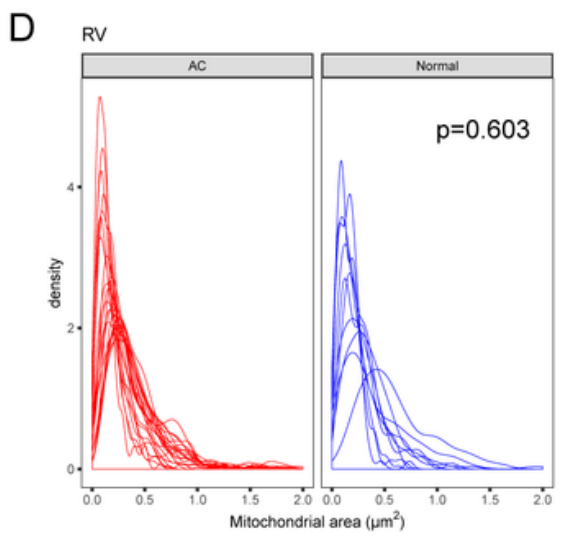

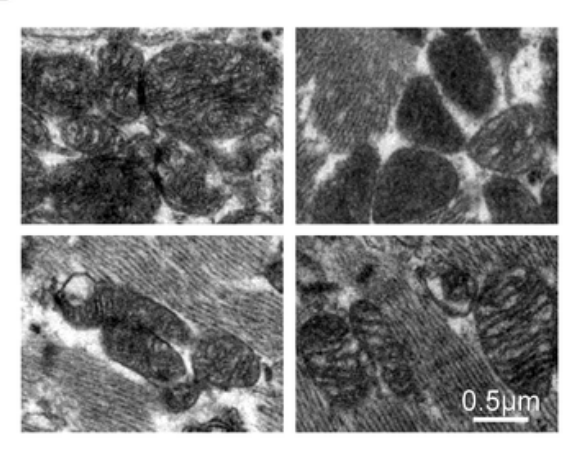

E

B

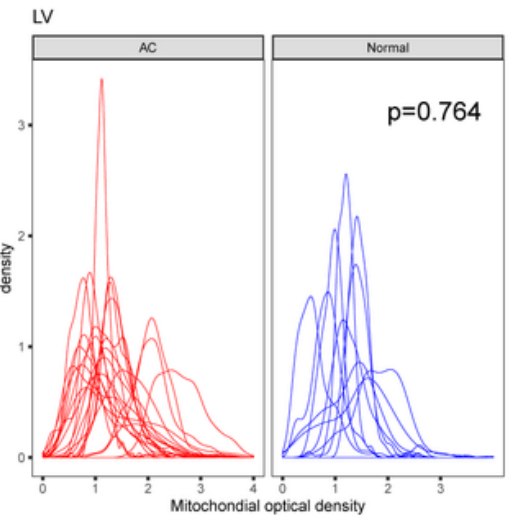

C เv

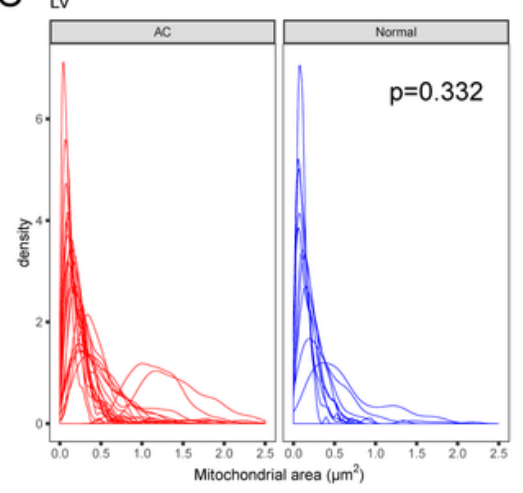

$F_{R Y}$

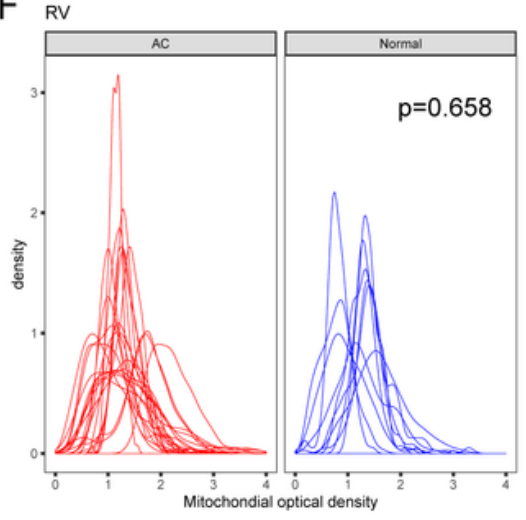

G

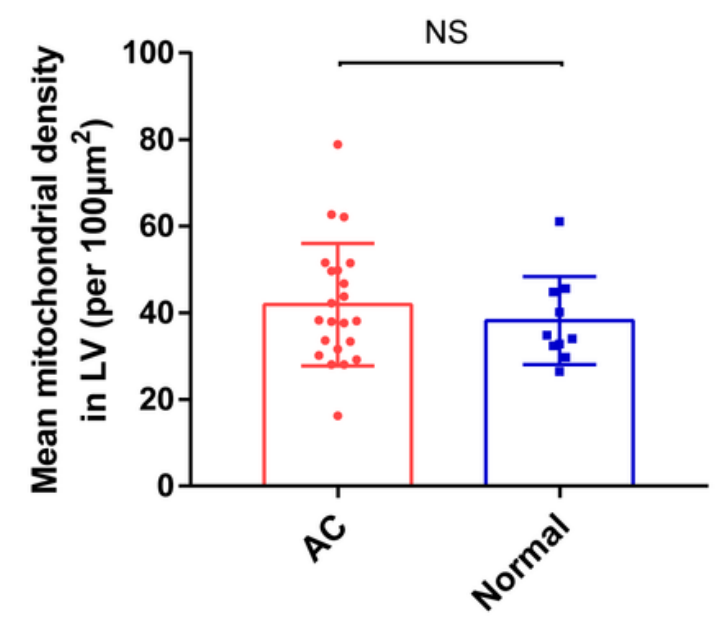

$\mathrm{H}$

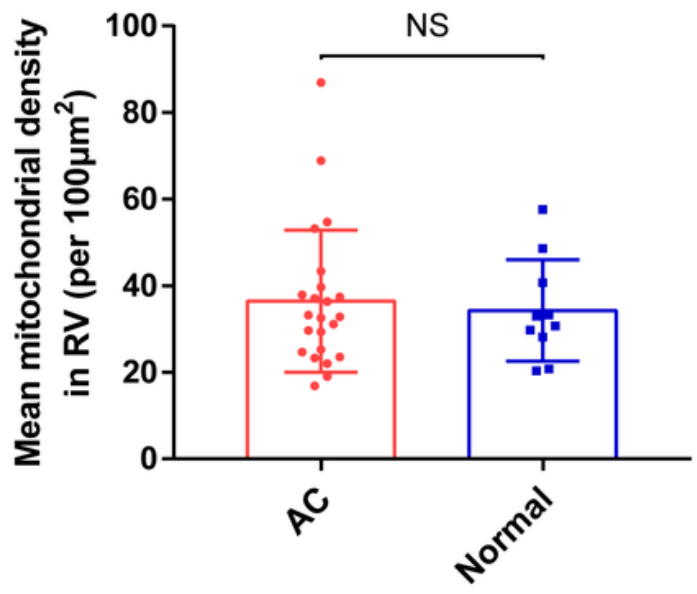

\section{Figure 6}

The ultrastructure comparison of mitochondria between AC and heart hearts: a. mitochondria in AC hearts; b. mitochondria in normal hearts; c. density profile of mitochondrial area in LV; d. density profile of mitochondrial area in RV; e. density profile of mitochondrial optical density in LV; f. density profile of mitochondrial optical density in RV; g. mean mitochondrion density in LV between AC and normal; $h$. mean mitochondrion density in RV between AC and normal. Magnification: X30000. 